\title{
Characterization and classification of PGI Moroccan Argan oils based on their FTIR fingerprints and chemical composition ${ }^{\text {it }}$
}

\author{
Mourad Kharbach ${ }^{\mathrm{a}, \mathrm{b}}$, Rabie Kamal ${ }^{\mathrm{c}}$, Mohammed Bousrabat ${ }^{\mathrm{a}}$, Mohammed Alaoui Mansouri ${ }^{\mathrm{a}}$, \\ Issam Barra ${ }^{\mathrm{a}}$, Katim Alaoui ${ }^{\mathrm{c}}$, Yahia Cherrah ${ }^{\mathrm{a}}$, Yvan Vander Heyden ${ }^{\mathrm{b}, *}$, Abdelaziz Bouklouze $^{\mathrm{a}}$ \\ ${ }^{a}$ Pharmaceutical and Toxicological Analysis Research Team, Laboratory of Pharmacology and Toxicology, Faculty of Medicine and Pharmacy, University Mohammed V, \\ Rabat, Morocco \\ b Department of Analytical Chemistry and Pharmaceutical Technology, CePhaR, Vrije Universiteit Brussel (VUB), Laarbeeklaan 103, B-1090 Brussels, Belgium \\ c Pharmacodynamics Research Team. Laboratory of Pharmacology and Toxicology, Faculty of Medicine and Pharmacy, University Mohammed V, Rabat, Morocco
}

\section{A R T I C L E I N F O}

\section{Keywords:}

Argan oil

Protected Geographical Indication

Chemometric classification

Principal Component Analysis

Partial Least Squares Discriminant Analysis

FTIR fingerprints

\begin{abstract}
A B S T R A C T
In this work Fourier Transform Infrared Spectroscopy (FTIR) was selected as a reliable, fast and non-destructive technique to record spectroscopic fingerprints of Moroccan Protected Geographical Indication (PGI) Argan oils. Classification and discrimination according to their five geographical origins (Ait-Baha, Agadir, Essaouira, Tiznit and Taroudant) was performed. A total of 120 PGI Argan oil samples were collected during four harvest seasons between 2011 and 2014.First, several physicochemical parameters were measured, i.e. free acidity, peroxide value, spectrophotometric indices, fatty acid composition, tocopherols and sterols content. Secondly, FTIR fingerprints were recorded for all samples. The data was subjected to Principal Component Analysis (PCA) for visualization and to reveal differences between samples. Classification models were developed by Partial Least Squares Discriminant Analysis (PLS-DA). Mathematical data pre-treatments were applied to improve the performance of the multivariate classification models. The results obtained, based on both the chemical composition and the spectroscopic fingerprints, indicate that PCA plots were able to distinguish the five sample classes. PLS-DA models based on either chemical composition or FTIR spectra gave a good prediction and an accurate discrimination between the samples from different regions.

The proposed approach with the FTIR spectra provided reliable results to classify the Moroccan PGI Argan oils from different regions in a rapid, inexpensive way requiring no prior separation procedure.
\end{abstract}

\section{Introduction}

The Argan culturing has a great economic and social importance in Southwestern Morocco. Argan forests cover an area of 800,000 ha, including the fertile Souss valley region, the foothills of the Anti-Atlas mountains, and the coast region between Essaouira and Agadir [1,2]. In fact, the resulting Argan oil has high health benefits in comparison to other oils [1], especially due to the special fatty acids composition [3], tocopherols [4], triacylglycerols [5], phytosterols [1,6,7], pigments and its antioxidant activity [8]. Argan oil may result from two processes of preparation: cold pression of unroasted kernels to provide cosmetic Argan oil, while roasted kernels are used to prepare edible Argan oil [9].

Nowadays the origin of food is essential for import and export products in order to ensure traceability for consumers. Information about food's origin is necessary to verify specifications and to guarantee quality because food from different origin may have distinct qualities $[10,11]$. In order to protect the original Argan products and to connect the concept of quality with the origin and geographical indication, Moroccan authorities have set up an internal protection apparatus according to the Argan PGI label. Since 25 January 2010, the PGI Argan is operational, which allows assigning the name "Huile d'Argane (Argan oil)" exclusively to products from the South West of Morocco. In particular, the PGI label has been established in order to obtain a product with a high economic value for commercialization in international markets.

Quality traceability and authenticity of the Argan oil have been the objects of numerous studies. Gas chromatography has been used to quantify and detect adulteration by campesterol [12]. Inductively coupled plasma atomic emission spectroscopy (ICP-AES) has been used to quantify eight trace elements for determining the authenticity of virgin Argan oils [13]. Recently, an high-performance liquid chromato-

\footnotetext{
Selected paper from XVI Chemometrics in Analytical Chemistry, 6-10 June 2016, Barcelona, Spain

* Corresponding author.

E-mail address: yvanvdh@vub.ac.be (Y. Vander Heyden).
} 
graphyevaporative light scattering detector (HPLC-ELSD) method has been applied for assessing the adulteration of Argan oil with vegetable oils [14].

Spectroscopic fingerprints associated with chemometric tools have been conducted in many up-to-date studies and have become interesting approaches for determining authenticity and quality control of foods [15]. The FTIR technique is widely used to determine or classify for instance, olive oils [16,17], wine [18], butter [19], the adulteration of extra virgin olive oils [20,21], the adulteration of Argan oil by soybean and sunflower oils [22] and the quantification of melamine in dairy milk [23]. In all above studies, different approaches combining FTIR fingerprints with chemometric tools have been applied for the identification, (geographical) classification or detection of adulterants. Chemical characterization associated with chemometric analysis has also been described in several studies, for instance, for classification of olive oils $[24,25]$ and of wine regarding its geographical origin $[26,27]$.

The aim of the present work was to investigate the possibility of using FTIR fingerprinting and chemical composition markers (free acidity, peroxide value, spectrophotometric indices, fatty acids, tocopherols and sterols) to classify PGI Argan oils according to the five different regions by applying chemometric methods (PCA and PLS-DA).

\section{Materials and methods}

\subsection{Sample collection}

A series of 120 PGI Argan oil samples (twenty four of each region) were sampled from five different Moroccan regions (Ait-Baha, Agadir, Essaouira, Tiznit and Taroudant) (Fig. 1) during four harvest seasons between 2011 and 2014. All samples are from unroasted kernels and are produced by the Women Cooperatives Markets from the five different regions, using mechanical extraction (Table 1).

\subsection{Instrumentation and spectral acquisition}

All infrared spectra were recorded in the range $4000-400 \mathrm{~cm}^{-1}$ by an ATR-FTIR spectrometer (Bruker Optics, Ettlingen, Germany) equipped with a deuterated triglycine sulfate detector. The instrument was equipped with an attenuated total reflectance (ATR) accessory. The number of scans for each spectrum was 24with a resolution $1 \mathrm{~cm}^{-1}$. Background spectra were collected at room temperature before each measurement.

\subsection{Determination of physico-chemical parameters}

Physicochemical quality parameters, such as acidity, peroxide value (PV), absorption coefficients at $270 \mathrm{~nm}\left(\mathrm{~K}_{270}\right)$ and at $232 \mathrm{~nm}\left(\mathrm{~K}_{232}\right)$, were determined according to their methodology described in the standard of the Commission of the European Community EEC/2568/9 [28]. Acidity and peroxide value are expressed in \% oleic acid and milliequivalents of active oxygen per kilogram of oil (meqO $\mathrm{O}_{2} / \mathrm{kg}$ ), respectively.

\subsection{Fatty acids}

\subsubsection{Nomenclature}

Saturated fatty acids (SFA): C14:0, myristic acid (tetradecanoic acid); C16:0, palmitic acid (hexadecanoic acid); C18:0, stearic acid (octadecanoic acid), C20:0, arachidic acid (eicosanoic acid). Monounsaturated fatty acid (MUFA): C18:1, oleic acid (9-octadecenoic acid); C20:1, gadoleic acid (11-eicosenoic acid); Poly-unsaturated fatty acid (PUFA): C18:2, linoleic acid (9, 12-octadecadienoic acid); C18:3, linolenic acid (9, 12, 15-octadecatrienoic acid).

\subsubsection{Fatty acid determination}

The fatty acid (FA) composition of the Argan oil samples was determined via trans-esterification into fatty acid methyl esters (FAME) according to European Official Methods of Analysis [28]. FAME were

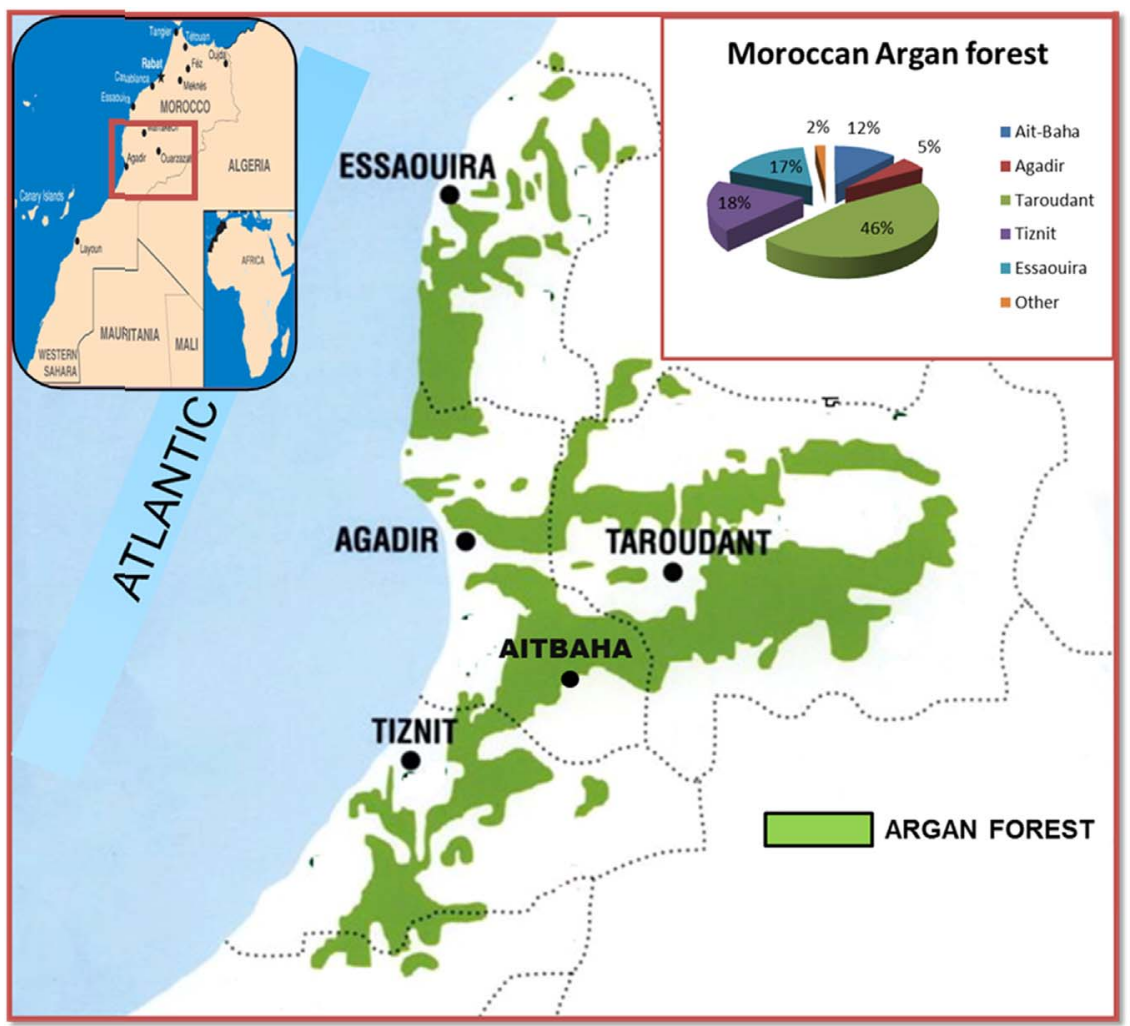

Fig. 1. Map of southwestern Moroccan Argan Forest. 
Table 1

Samples geographical origins and their class label; "Moroccan Argan forest" represents the \% covered by the Argan trees of the studied regions.

\begin{tabular}{|c|c|c|c|c|c|c|}
\hline \multirow[t]{2}{*}{ Geographical origin } & \multirow[t]{2}{*}{ Code } & \multirow[t]{2}{*}{ Number of samples } & \multicolumn{2}{|c|}{ Number of samples in sub sets } & \multirow[t]{2}{*}{ Studied localities } & \multirow[t]{2}{*}{ Moroccan Argan forest } \\
\hline & & & Calibration & Validation & & \\
\hline Agadir & A & 24 & $18(75 \%)$ & $6(25 \%)$ & 13 & $5 \%$ \\
\hline Ait-Baha & A-B & 24 & $18(75 \%)$ & $6(25 \%)$ & 15 & $12 \%$ \\
\hline Essaouira & $\mathrm{E}$ & 24 & $18(75 \%)$ & $6(25 \%)$ & 19 & $17 \%$ \\
\hline Taroudant & $\mathrm{T}$ & 24 & $18(75 \%)$ & $6(25 \%)$ & 21 & $46 \%$ \\
\hline Tiznit & Tiz & 24 & $18(75 \%)$ & $6(25 \%)$ & 18 & $18 \%$ \\
\hline Total & - & 120 & $90(75 \%)$ & $30(25 \%)$ & 86 & $98 \%$ \\
\hline
\end{tabular}

measured by a model 6890 Agilent Technologies gas chromatograph (Wilmington, DE, USA) equipped with a flame ionization detector (FID) and a HP-88 capillary column (100 m x $0.25 \mathrm{~mm}$ ID x $0.20 \mu \mathrm{m}$ film) (Agilent Technologies Spain, Madrid). The carrier gas was helium, with a flow of $1 \mathrm{~mL} / \mathrm{min}$. The temperatures of the injector and detector were set at 230 and $250{ }^{\circ} \mathrm{C}$, respectively. Oven temperature was held at $210^{\circ} \mathrm{C}$. Eight FA were identified from their retention times. The results are expressed in $\%(\mathrm{~g} / 100 \mathrm{~g}$ oil).

\subsection{Tocopherols determination}

Tocopherols were assessed using the AOCS Method Ce8-89 [29]. A solution of Argan oil in n-hexane was analyzed on an Agilent HPLC system(1100 series, Germany) equipped with a fluorescence detector; the column wasC18-Varian $(25 \mathrm{~cm} \times 4.6 \mathrm{~mm}$; Varian, ChromSpher, Middelburg, The Netherlands). The mobile phase is a mixture of hexane/2-propanol $(98.5: 1.5 \mathrm{v} / \mathrm{v})$ with a flow rate of $1 \mathrm{ml} / \mathrm{min}$. The excitation and emission wavelengths are 295 and330 nm, respectively.

\subsection{Sterol analysis}

Sterol composition of PGI Argan oil was determined according to the separation method of the NP ISO 12228:2002 [30]. The same apparatus as for FA was used with a DB- 5 capillary column $(30 \mathrm{~m} \times 0.25$ $\mathrm{mm}$ ID $\times 0.25 \mu \mathrm{m}$ film) (Agilent). The column temperature was maintained at $280^{\circ} \mathrm{C}$. The injector and the detector were both set at $290^{\circ} \mathrm{C}$. The carrier gas was helium, with a flow of $2 \mathrm{~mL} / \mathrm{min}$. Sterol identification was achieved by comparing the relative retention times from sample peaks with those obtained from sterol standards. The latter were also used for quantification. The amount of sterols is expressed in \% individual sterols and the total sterol content in $\mathrm{mg} / 100 \mathrm{~g}$ oil.

\subsection{Chemometric analysis}

PCA is an unsupervised technique visualizing the data. PCA displayed the main information and permitted evaluation of the differences and similarities of samples. The PCA model decomposes the initial data (matrix $\mathbf{X}$ ) in a scores, a loadings and a residuals matrix. The number of principal components (PCs) considered depends on the data complexity, where these latter PCs explained quasi the total variance. A scores plot represents the variation or similarity in the samples of the data set, while the loadings plot represents the relations between the variables [31].

PLS-DA is a supervised analysis, based on calculating latent variables, which discriminates between two sample classes. It creates a new response, coded with a binary code, 0 or 1 , where 1 indicates the concept "belonging to a category", while label 0 refers to "not belonging to the category" $[32,33]$. The performance of the models was evaluated in terms of the root mean squared error of calibration (RMSEC),the root mean squared error of prediction (RMSEP), the coefficient of determination of model fitting $\left(\mathrm{R}^{2}\right)$ and prediction $\left(\mathrm{Q}^{2}\right)$.In general, a good model should have low and similar RMSEC and RMSEP values, and high $\mathrm{R}^{2}$ and $\mathrm{Q}^{2}$ coefficients.Samples with predicted values below 0.5 were assigned as outside a give class, while samples with predicted values above 0.5 were assigned as belonging to the defined class [32].

\subsection{Software}

The significance of differences between multiple averages was determined by one-way analysis of variance (ANOVA), followed by a Tukey's post hoc test at a $5 \%$ level to evaluate the influence of the geographic origin on the analysed parameters.

Data processing of spectra and the application of chemometric tools as PCA and PLS-DA were performed with the Unscrambler, X, software, version 10.0 (Camo, Norway).

\section{Results and discussion}

\subsection{Physicochemical quality assessment}

Acidity, peroxide value and UV absorption $\left(\mathrm{K}_{232}\right.$ and $\left.\mathrm{K}_{270}\right)$ are critical parameters to assess the quality and to measure the oxidative deterioration of edible oil. As shown in Table 2, the acidity, peroxide value, $K_{232}$ and $K_{270}$ values of all analyzed samples were lower than $0.80 \%, 15 \mathrm{meqO}_{2} / \mathrm{kg}, 2.52$ and 0.35 , respectively, which are the legal limits of specification required by the Moroccan Normalization guidelines [34]. The ANOVA with Tukey's test applied on the acidity, peroxide value, $\mathrm{K}_{232}$ and $\mathrm{K}_{270}$ indicated statistically significant differences between the studied samples according to their geographic origin ( $\mathrm{p}<0.05)$.The highest mean values for acidity were found for AitBaha oils $(0.33 \%)$, and the lowest $(0.21 \%)$ for Taroudant and Tiznit samples. The peroxide values are1.31 and $2.21 \mathrm{meqO}_{2} / \mathrm{kg}$ for Agadir and Ait-Baha samples, respectively. Besides the geographical origin, the time of harvest, the extraction process of the Argan oil and the storage period may also cause oxidation and increase the peroxide value [35]. The averages of the specific absorbances $\mathrm{K}_{232}$ and $\mathrm{K}_{270}$ ranged between $1.17-1.87$ and 0.21 to 0.33 , respectively. The low values of these quality parameters confirmed the good quality of the analyzed PGI Argan oils in the current study; they allow classifying the studied samples in the Virgin category [34].

\subsection{Fatty acid composition}

The major fatty acids expected in Argan oil are oleic (C18:1), linoleic (C18:2), palmitic (C16:0) and stearic (C18:0) acids [1]. The PGI Argan oils under study were characterized by three major fatty acids: palmitic (C16:0), oleic (C18:1) and linoleic (C18:2). Myristic acid (C14:0), linolenic acid (C18:3) and gadoleic acid (C20:1) have smaller amounts in all samples (Table 2). ANOVA with Tukey's test applied to the individual fatty acid compositions, showed statistically significant differences between samples from different geographic origin $(\mathrm{p}<$ 0.05).

Polyunsaturated fatty acids are very important for human nutrition [8]. Linoleic acid (C18:2), the dominant PUFA in the PGI Argan oils varied between 30.5 and $35.4 \%$ depending on the geographical origin, 
Table 2

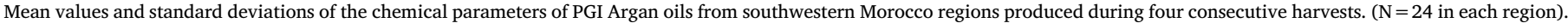

\begin{tabular}{|c|c|c|c|c|c|c|}
\hline \multirow[b]{2}{*}{ Chemical parameters } & \multirow[b]{2}{*}{ VAO regulation } & \multicolumn{5}{|c|}{ Geographical origin } \\
\hline & & Agadir & Ait-Baha & Essaouira & Taroudant & Tiznit \\
\hline Acidity (\%) & $\leq 0.8$ & $0.28^{\mathrm{b}} \pm 0.02$ & $0.32^{\mathrm{d}} \pm 0.02$ & $0.22^{\mathrm{a}} \pm 0.01$ & $0.35^{\mathrm{e}} \pm 0.02$ & $0.30^{\mathrm{c}} \pm 0.02$ \\
\hline Peroxide value (meq $\mathrm{O}_{2} / \mathrm{kg}$ ) & $\leq 15$ & $2.21^{\mathrm{e}} \pm 0.15$ & $1.31^{\mathrm{a}} \pm 0.14$ & $1.86^{\mathrm{c}} \pm 0.19$ & $1.93^{\mathrm{d}} \pm 0.18$ & $1.74^{\mathrm{b}} \pm 0.16$ \\
\hline $\mathrm{K}_{232}$ & $\leq 2.52$ & $1.87^{\mathrm{e}} \pm 0.09$ & $1.17^{\mathrm{a}} \pm 0.02$ & $1.26^{\mathrm{c}} \pm 0.03$ & $1.30^{\mathrm{d}} \pm 0.02$ & $1.19^{\mathrm{b}} \pm 0.03$ \\
\hline$K_{270}$ & $\leq 0.35$ & $0.22^{\mathrm{b}} \pm 0.01$ & $0.33^{c} \pm 0.02$ & $0.22^{\mathrm{b}} \pm 0.01$ & $0.21^{\mathrm{a}} \pm 0.02$ & $0.21^{\mathrm{a}} \pm 0.02$ \\
\hline \multicolumn{7}{|l|}{ Fatty Acids (\% total fatty acid) } \\
\hline $\mathrm{C} 14: 0$ & $\leq 0.20 \%$ & $0.16^{b} \pm 0.02$ & $0.15^{\mathrm{a}} \pm 0.02$ & $0.15^{\mathrm{b}} \pm 0.03$ & $0.15^{\mathrm{b}} \pm 0.02$ & $0.15^{\mathrm{b}} \pm 0.02$ \\
\hline C16:0 & $11.50-15.00 \%$ & $12.66^{\mathrm{b}} \pm 0.41$ & $14.02^{\mathrm{d}} \pm 0.37$ & $11.85^{\mathrm{a}} \pm 0.33$ & $14.64^{e} \pm 0.31$ & $13.82^{c} \pm 0.39$ \\
\hline C18:0 & $4.30-7.20 \%$ & $4.77^{\mathrm{b}} \pm 0.23$ & $6.80^{\mathrm{d}} \pm 0.35$ & $4.65^{\mathrm{a}} \pm 0.21$ & $5.62^{\mathrm{c}} \pm 0.30$ & $6.86^{d} \pm 0.29$ \\
\hline $\mathrm{C} 20: 0$ & $\leq 0.50 \%$ & $0.39^{c} \pm 0.05$ & $0.35^{\mathrm{b}} \pm 0.03$ & $0.35^{\mathrm{b}} \pm 0.04$ & $0.36^{\mathrm{b}} \pm 0.02$ & $0.29^{\mathrm{a}} \pm 0.04$ \\
\hline C18:1 & $43.10-49.00 \%$ & $44.92^{\mathrm{b}} \pm 0.49$ & $46.85^{c} \pm 0.51$ & $43.93^{a} \pm 0.49$ & $48.56^{c} \pm 0.53$ & $47.28^{c} \pm 0.66$ \\
\hline $\mathrm{C} 20: 1$ & $\leq 0.50 \%$ & $0.42^{\mathrm{c}} \pm 0.05$ & $0.32^{\mathrm{b}} \pm 0.02$ & $0.47^{d} \pm 0.02$ & $0.41^{\mathrm{c}} \pm 0.04$ & $0.29^{\mathrm{a}} \pm 0.05$ \\
\hline $\mathrm{C} 18: 2$ & $29.30-36.00 \%$ & $30.54^{\mathrm{a}} \pm 0.72$ & $33.11^{b} \pm 0.53$ & $30.26^{\mathrm{a}} \pm 0.76$ & $35.41^{\mathrm{d}} \pm 0.65$ & $34.09^{c} \pm 0.62$ \\
\hline C18:3 & $\leq 0.30 \%$ & $0.13^{\mathrm{b}} \pm 0.13$ & $0.29^{d} \pm 0.04$ & $0.11^{\mathrm{a}} \pm 0.03$ & $0.26^{\mathrm{c}} \pm 0.02$ & $0.25^{c} \pm 0.04$ \\
\hline SFA & & $17.98^{\mathrm{a}} \pm 0.46$ & $21.32^{b} \pm 0.60$ & $17.00 \pm 0.45$ & $20.77^{b} \pm 0.37$ & $21.13^{\mathrm{b}} \pm 0.50$ \\
\hline MUFA & & $45.34^{\mathrm{a}} \pm 0.49$ & $47.17^{\mathrm{b}} \pm 0.52$ & $44.40^{\mathrm{a}} \pm 0.49$ & $48.97^{c} \pm 0.54$ & $47.57^{\mathrm{b}} \pm 0.68$ \\
\hline PUFA & & $30.67^{\mathrm{a}} \pm 0.72$ & $33.39^{b} \pm 0.55$ & $30.36^{\mathrm{a}} \pm 0.75$ & $35.66^{c} \pm 0.65$ & $34.34^{b} \pm 0.63$ \\
\hline \multicolumn{7}{|l|}{ Tocopherols (mg/kg oil) } \\
\hline$\alpha$-tocopherol & $18-75$ & $34.98^{\mathrm{b}} \pm 2.17$ & $69.86^{\mathrm{e}} \pm 1.94$ & $25.01^{\mathrm{a}} \pm 2.57$ & $41.51^{c} \pm 3.36$ & $57.19^{d} \pm 3.64$ \\
\hline$\beta$-tocopherol & 01-mai & $1.61^{\mathrm{b}} \pm 0.31$ & $3.89^{d} \pm 0.35$ & $1.21^{\mathrm{a}} \pm 0.14$ & $3.02^{\mathrm{c}} \pm 0.40$ & $4.56^{\mathrm{e}} \pm 0.42$ \\
\hline $\mathrm{y}$-tocopherol & $640-810$ & $664.44^{\mathrm{a}} \pm 22.46$ & $739.89^{c} \pm 8.77$ & $802.36^{\mathrm{e}} \pm 6.62$ & $716.17^{\mathrm{b}} \pm 7.09$ & $777.34^{\mathrm{d}} \pm 13.56$ \\
\hline$\delta$-tocopherol & $54-110$ & $71.31^{\mathrm{b}} \pm 2.71$ & $92.57^{\mathrm{d}} \pm 3.25$ & $58.55^{\mathrm{a}} \pm 3.26$ & $104.36^{\mathrm{e}} \pm 4.42$ & $80.17^{\mathrm{c}} \pm 2.83$ \\
\hline Total tocopherol & $600-900$ & $772.34^{\mathrm{a}} \pm 24.13$ & $906.21^{\mathrm{d}} \pm 8.80$ & $887.12^{c} \pm 8.64$ & $865.25^{\mathrm{b}} \pm 7.95$ & $919.26^{e} \pm 14.77$ \\
\hline \multicolumn{7}{|l|}{ Sterols (\% total seterols) } \\
\hline Cholesterol & $\leq 0.40$ & $0.18^{\mathrm{b}} \pm 0.02$ & $0.33^{\mathrm{d}} \pm 0.22$ & $0.26^{\mathrm{c}} \pm 0.02$ & $0.38^{\mathrm{e}} \pm 0.02$ & $0.11^{\mathrm{a}} \pm 0.03$ \\
\hline Campesterol & $\leq 0.40$ & $0.26^{c} \pm 0.02$ & $0.11^{\mathrm{a}} \pm 0.02$ & $0.18^{\mathrm{b}} \pm 0,02$ & $0.38^{\mathrm{e}} \pm 0.02$ & $0.33^{\mathrm{d}} \pm 0.02$ \\
\hline$\Delta-7$-Avenasterol & $4.00-7.00$ & $4.96^{\mathrm{b}} \pm 0.19$ & $6.69^{\mathrm{e}} \pm 0,21$ & $5.53^{c} \pm 0.16$ & $6.11^{\mathrm{d}} \pm 0.20$ & $4.34^{\mathrm{a}} \pm 0.20$ \\
\hline Stigma-8-22-dien-3 $\beta$-ol & $3.20-5.70$ & $4.01^{\mathrm{b}} \pm 0.14$ & $4.57^{\mathrm{c}} \pm 0.16$ & $5.12^{\mathrm{d}} \pm 0.15$ & $5.62^{\mathrm{e}} \pm 0.11$ & $3.43^{\mathrm{a}} \pm 0.18$ \\
\hline Schottenol & $44.00-49.00$ & $45.52^{\mathrm{b}} \pm 0.33$ & $46.41^{c} \pm 0.30$ & $47.41^{d} \pm 0.30$ & $48.74^{e} \pm 0.47$ & $44.48^{\mathrm{a}} \pm 0.34$ \\
\hline Spinasterol & $34.00-44.00$ & $37.12^{\mathrm{b}} \pm 0.50$ & $38.99^{c} \pm 0.60$ & $41.11^{\mathrm{d}} \pm 0.54$ & $43.63^{e} \pm 0.86$ & $34.91^{\mathrm{a}} \pm 0.58$ \\
\hline Total sterols (mg/100 g oil) & $\leq 220 \mathrm{mg} / 100 \mathrm{~g}$ & $142.09^{b} \pm 10.59$ & $167.09^{c} \pm 11.84$ & $184.60^{\mathrm{d}} \pm 15.84$ & $214.75^{\mathrm{e}} \pm 14.05$ & $137.60^{\mathrm{a}} \pm 15.72$ \\
\hline
\end{tabular}

Significant differences in one row are indicated with different superscript letters (comparison between the studied regions, Tuckey's test).

VAO, Virgin Argan oil.

SFA, Saturated Fatty Acids; MUFA, Monounsaturated Fatty Acids; and PUFA, Polyunsaturated Fatty Acids.

The bold numbers represent the highest mean in each class.

while linolenic acid (C18:3) occurs in traces. MUFA and PUFA appeared as the highest fractions in the Taroudant samples with $49.0 \%$ and $35.7 \%$ of the total fatty acids, respectively. Oleic acid (C18:1) was the main MUFA and is present in higher concentrations (43.6-48.6\% of the total fatty acids). The palmitic (C16:0) and linoleic (C18:2) acid contents varied between $12.7-14.6 \%$ and $30.3-35.4 \%$, respectively, depending on the geographical area. Variations in oleic and linoleic acid content observed in the Argan oils are related to the process of extraction and the environmental conditions [9].

Samples from the Ait-Baha region are represented by the highest total SFA fraction $(21.32 \% \pm 0.60 \%)$, while it is also rich in linolenic acid (C18:3), which was the dominant PUFA ranging from $0.22 \%$ to $0.36 \%$ in these samples. The Essaouira region is characterized by rather low amounts of SFA, MUFA and PUFA (Table 2). The palmitic acid (C16:0) levels increase when going from the plain to the highlands (Taroudant to Essaouira). These results are in agreement with the findings of other researchers: it was reported that the oleic acid (C18:1) levels increase with record precipitation and those of linoleic acid (C18:2) with altitude [36]. The global variability of fatty acid composition in Argan oils can be attributed to various factors, including geographical origin and the effect of climate, particularly precipitation $[37,38]$.

The limits composition is established by the Moroccan Normalization guidelines (N.M. 08.5.090) [34]. The fatty acid composition found in the investigated PGI Argan oils samples is within the normal ranges for "Virgin Argan oil" considered by these standards (Table 2).

\subsection{Tocopherol composition}

The tocopherol composition is important to prevent lipid oxidation processes in Argan oils. Numerous studies have demonstrated that they play an important role in the human organism and contribute to the bioactivity in foods stuffs [39]. Vitamin E determination has also been used for the authenticity and quality assessment of oils, based on qualitative and quantitative profiles [40].

In our study, four major tocopherols were quantified; $\gamma$-tocopherol was the major compound, followed by $\delta, \alpha$ and $\beta$-tocopherols, respectively (Table 2). The highest total tocopherol contents occurs in samples from Ait-Baha $(919 \mathrm{mg} / \mathrm{kg}$ ) and Tiznit $(906 \mathrm{mg} / \mathrm{kgoil})$, respectively. Furthermore, the influence of geographical origin on the individual and the total tocopherol contents was observed to be significant using Tukey's test $(\mathrm{p}<0.05)$. As shown in Table 2, both the total tocopherols content and the amounts of individual tocopherols varied significantly depending on the geographical zone. Agadir $(772 \mathrm{mg} / \mathrm{kg}$ ), Essaouira $(887 \mathrm{mg} / \mathrm{kg}$ ) and Taroudant $(865 \mathrm{mg} / \mathrm{kgof}$ oil) had the lowest total tocopherols contents among the five regions examined. The $\gamma$-tocopherol was the most abundant tocopherol, being found in the range 664$802 \mathrm{mg} / \mathrm{kg}$, followed by $\delta$-tocopherol, with mean values ranging between $58-104 \mathrm{mg} / \mathrm{kg}$ and $\alpha$-tocopherol between $35-70 \mathrm{mg} / \mathrm{kg}$ oil. However, roasting Argan kernels before oil extraction affects the $\alpha$ tocopherol composition and the level is inferior to the unroasted kernels [9]. The highest mean value for $\beta$-tocopherols was $4.56 \mathrm{mg} / \mathrm{kg}$, and the lowest $1.21 \mathrm{mg} / \mathrm{kg}$.

These results on the content in tocopherols allow classifying the samples from Agadir, Essaouira and Taroudant within the category of 
"Virgin Argan oil", according to the classification established by the Moroccan normalization guidelines [34]. This is not the case for the samples from Ait-Baha and Tiznit.

\subsection{Sterol composition}

Phytosterols are nutritionally important lipids making up the largest partof the non-saponificable fraction of PGI Argan oils. Campesterol, cholesterol, $\Delta-7$-avenasterol, stigma-8-22-dien-3ß-ol, schottenol and spinasterol are the dominant sterols of Argan oil [9]. Sterols determination also permits classification of the type of Argan oil in, for instance, extra virgin, virgin and pure [34]. The analysed PGI Argan oils contained more than $137 \mathrm{mg} \%(\mathrm{~m} / \mathrm{m})$ total sterols, with a median value of $167 \mathrm{mg} / 100 \mathrm{~g}$, and extremes of 137 and $215 \mathrm{mg} / 100 \mathrm{~g}$ originating from Tiznit and Taroudant, respectively (Table 2). The total sterols content varied significantly depending on the production region (Tukey's test, $\mathrm{p}<0.05$ ).

The schottenol fraction was remarkably high, i.e. about $48-49 \%$ in the Taroudant area. This was also the case for the spinasterol content in the oils from Taroudant, with a range from 42to 47\%. Significant differences (Tukey's tests $\mathrm{p}<0.05$ ) on all individual sterol compositions were seen. The campestrol and cholesterol fractions were below the established limit of $0.40 \%$. The campesterol content can be used to assess the degree of purity of the Argan oil and to detect fraudulently added oils [12].

The highest and lowest $\Delta-7$-avenasterol fractions were between 4 and $7 \%$ found in the Tiznit and Taroudant regions. Furthermore, trace fractions of others sterols were found in all evaluated oil samples. Research has shown that numerous factors affect the content and composition of sterols in Argan oil, such as the geographical growing area, climatic conditions, kernel quality, the oil extraction system (mechanical or traditional) and storage conditions [9,41,42]. However, the sterol composition was reported to remain qualitatively and quantitatively constant during the storage period or during accelerated storage conditions. It is neither actively involved in the conservation of Argan oil nor in its flavor [35]. All analyzed PGI oils samples fulfilled the limit set by the Moroccan normalization guideline for the sterol content [34].

\subsection{Classification of Argan oil according to geographical origin based on chemical composition}

In addition to the genetic variety of the trees, Argan oils may present very different characteristics depending on their geographical origin. Several factors affect the oil quality (e.g.: extraction method, environmental conditions, stage of ripening at harvest and storage conditions) [9,42]. It is important to relate the chemical composition of an oil with its geographical origin.

\subsubsection{PCA analysis}

PCA was applied to the autoscaled data to locate any existing clustering of samples based on the chemical composition. Five groups are clearly distinguished (Fig. 2(a)) on the PC1-PC2 score plot. The first two principal components explained $63 \%$ of the total variability. The score plot indicates that classification of the samples according to their geographical origin based on the chemical composition should be possible.

The loading plot represents the weights of the variables on the different PCs. Fig. 2(b), shows that some chemical parameters do not have an important weight at the considered PCs: variables placed in the middle of the plot (close to the axis origin). However, they can be important in higher PCs.

\subsubsection{PLS-DA classification}

All 22chemical parameters determined (Table 2) were found to be significant (Tukey's test, $\mathrm{p}<0.05$ ) for the differentiation of PGI Argan oils. The loading plot indicates that "campesterol, $\gamma$-tocopherol and C14:0" had low weights for the two first PCs (63\% of total of the total variance). However, they can be important for higher PCs and the Tukey's test was significant for all the 22 variables, indicating that all variables are important to construct the classification model. The PLSDA was applied to the autoscaled data matrix composed of 120 samples and 22 variables in order to develop discrimination models for the classification of PGI Argan oils. The models were evaluated using $\mathrm{R}^{2}$, $\mathrm{Q}^{2}$, RMSEC and RMSEP (Table 3(a)). A model was established from 90 samples (18 samples from each group were randomly selected, see Table 1), while the remaining 30 samples ( 6 samples from each class) were considered as an external validation set (Table 1). The leave-oneout cross-validation method was used to select the optimal number of latent variables (LVs) for each calibration model. The best models were obtained using 4LVs for classes A, A-B, E and T, and 5 LVs for Tiz. The quality parameters indicate $\mathrm{R}^{2}$ and $\mathrm{Q}^{2}$ values which range between 96.7 - 98.7\% and 96.3 - 98.3\%, respectively. The classification errors (RMSEC and RMSEP) to evaluate the performance of the established models on predicting new samples varied from 0.046 to 0.073 and 0.053 to 0.077 , respectively. These models were applied to classify the 30 test set samples (Table 4a). All validation samples are clearly assigned to their proper classes. Their predicted y values are comprised between 0.828 and 1.125 . Correct classification rates of $100 \%$ were obtained on the external validation set samples. These findings indicate that the PLS-DA models were accurate.

\subsection{Classification of Argan oils according to geographical origin based on FTIR spectra}

As it was possible to classify samples based on their chemical composition, it is interesting to verify this classification on the basis of the spectral data.

Typical spectra obtained for all PGI Argan oil samples are presented on Fig. 3a. The Argan oil spectra are dominated by some peaks absorbances; 2924 and $2852 \mathrm{~cm}^{-1}$, due to symmetrical and asymmetrical stretching of $-\mathrm{CH}_{2} ; 1743 \mathrm{~cm}^{-1}, \mathrm{C}=\mathrm{O}$ stretching vibrations; 1463 and $1377 \mathrm{~cm}^{-1}, \mathrm{CH}_{2}$ and $\mathrm{CH}_{3}$ scissoring vibrations; $1238,1163,1114$ and $1099 \mathrm{~cm}^{-1},-\mathrm{C}-\mathrm{O}$ stretching vibrations. The bands at $721 \mathrm{~cm}^{-1}$ correspond to $\mathrm{CH}_{2}$ rocking $[43,44]$.

\subsubsection{PCA analysis}

In order to improve the discrimination, the spectra have been pretreated. Maximum peak height normalization by dividing each signal value for one sample by the sum of all signal values for that sample and mean centering were applied on all spectra $\left(4000-400 \mathrm{~cm}^{-1}\right)$ and on a reduced data set (two segments of the FTIR spectra were removed prior to the data treatment, the first between $4000-3028 \mathrm{~cm}^{-1}$ and the second between $2766-1786 \mathrm{~cm}^{-1}$ because of low signal-to-noise ratio values). The two first PCs account for $98 \%$ and $99 \%$ of the total variance for the full and the reduced data set, respectively. In Fig. 3b it is shown that the reduced spectra from the five studied regions are clearly separated. The groups corresponding to the classes A, E and T are rather close. Regions $\mathrm{A}, \mathrm{E}$ and $\mathrm{T}$ represent more than $68 \%$ of the Argan forest (Fig. 1). A and E are two oceanic coastal regions with hot humid and arid bioclimate. The T-region ( $80 \mathrm{~km}$ east of Agadir) is surrounded by two mountain chains (High Atlas and Anti-Atlas) and has a hot semi-arid bioclimate, which is in fact the most different from the $\mathrm{A}$ and $\mathrm{E}$ classes. Also in the $\mathrm{T}$ class, temperature average values reach $30^{\circ} \mathrm{C}$ in summer and the average winter minimum is between 3 and $8{ }^{\circ} \mathrm{C}$. The classes A-B and Tiz (Fig. 1) are geographically close. They have similar climate conditions. Their winter is relatively warm and humid with a temperature of $25^{\circ} \mathrm{C}$ and the summer is hot arid with temperatures around $30{ }^{\circ} \mathrm{C}$. The difference between the annual precipitations can also be a determining factor between two classes. The classes A-B and Tiz are characterized by an arid Mediterranean bioclimate, Saharan areas with desert nature and they are influenced 

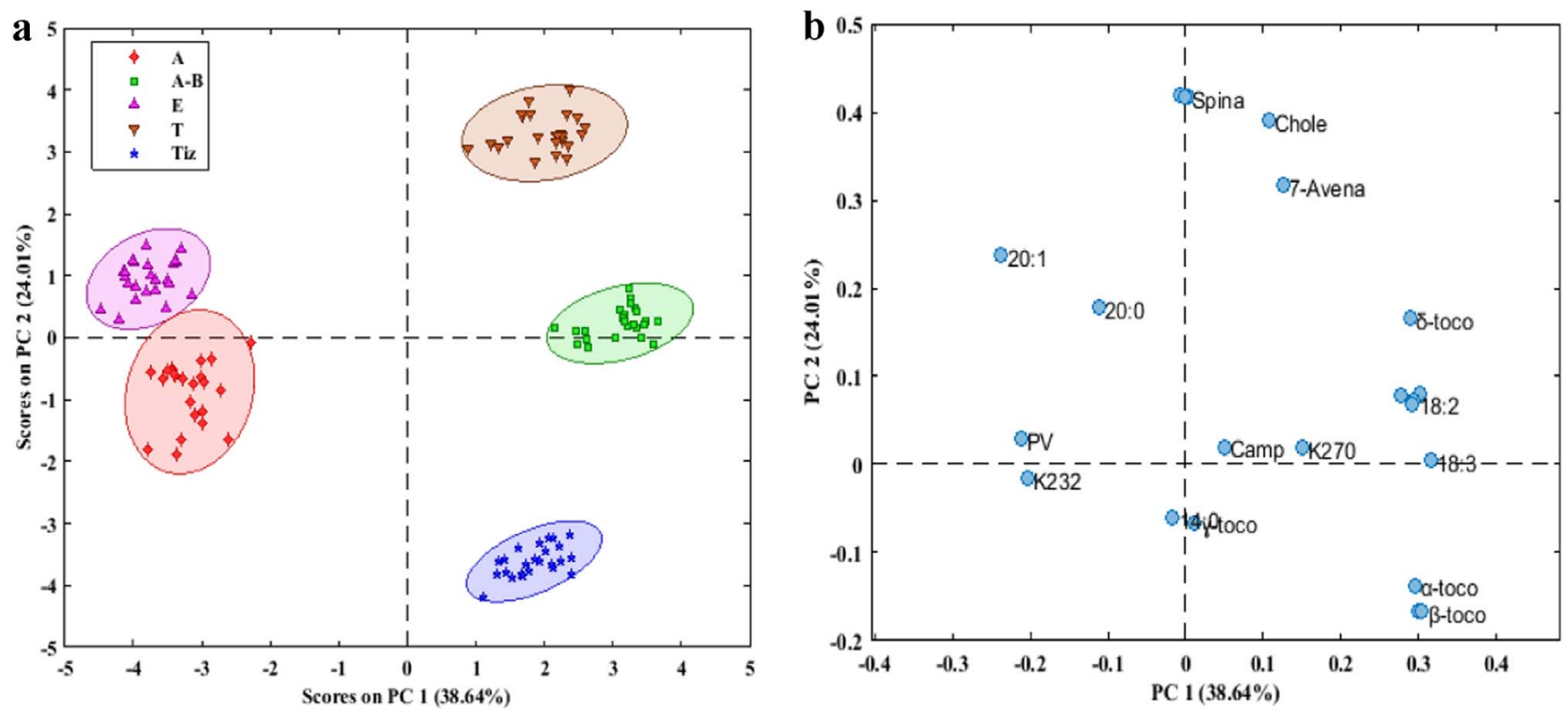

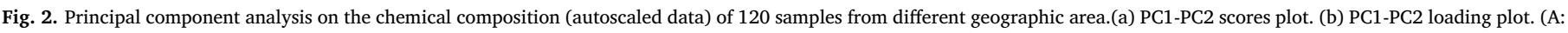
Agadir; A-B: Ait-Baha; E: Essaouira; T: Taroudant; Tiz: Tiznit). Abbreviations of the loadings: see Table 2.

Table 3

Quality parameters achieved by the PLS-DA classification: (a) based on the chemical composition, (b) based on the FTIR spectra and (c) based on the reduced FTIR spectra.

(a)

\begin{tabular}{llllll}
\hline Class & LVs & $\mathrm{R}^{2}$ & $\mathrm{Q}^{2}$ & RMSEC & RMSEP \\
\hline $\mathrm{A}$ & 4 & 96.73 & 96,26 & 0.073 & 0.077 \\
$\mathrm{~A}-\mathrm{B}$ & 4 & 96.97 & 96,62 & 0.069 & 0.074 \\
$\mathrm{E}$ & 4 & 97.72 & 97,43 & 0.060 & 0.064 \\
$\mathrm{~T}$ & 4 & 97.01 & 96,69 & 0.069 & 0.074 \\
Tiz & 5 & 98.67 & 98,32 & 0.046 & 0.053 \\
(b) & & & & & \\
Class & $\mathrm{LVs}$ & $\mathrm{R}^{2}$ & $\mathrm{Q}^{2}$ & RMSEC & RMSEP \\
A & 4 & 99.70 & 99.68 & 0.022 & 0.023 \\
A-B & 5 & 99.14 & 98.95 & 0.037 & 0.041 \\
$\mathrm{E}$ & 4 & 99.95 & 99.94 & 0.009 & 0.009 \\
$\mathrm{~T}$ & 5 & 99.74 & 99.71 & 0.020 & 0.022 \\
Tiz & 4 & 99.51 & 99.44 & 0.028 & 0.030 \\
(c) & & & & & \\
Class & $\mathrm{LVs}$ & $\mathrm{R}^{2}$ & $\mathrm{Q}^{2}$ & RMSEC & RMSEP \\
A & 5 & 99.47 & 99.24 & 0.029 & 0.036 \\
A-B & 5 & 99.94 & 99.93 & 0.010 & 0.011 \\
E & 5 & 99.60 & 99.53 & 0.025 & 0.027 \\
T & 5 & 99.39 & 99.22 & 0.031 & 0.036 \\
Tiz & 4 & 99.71 & 99.67 & 0.021 & 0.023 \\
\hline
\end{tabular}

LVs: number of latent variables; $\mathrm{R}^{2}$ : Coefficient of determination; $\mathrm{Q}^{2}$ : coefficient of prediction; RMSEC: root mean squared error of calibration; RMSEP: roots mean squared error of prediction.

by the variability of annual rainfall ranging from 100 to $250 \mathrm{~mm}$. Summarized, the PCA plot mainly indicates the clear discrimination between five classes corresponding to the five regions. A geographical classification of the PGI Argan oils based on their FTIR spectra is discussed further.

\subsubsection{PLS-DA discrimination}

To expand the differences between the classes, pre-treatment on the FTIR spectra was applied. The same data pretreatment as for PCA was used. The prediction ability of the PLS-DA model developed was evaluated by the leave-one-out cross validation procedure. The quality parameters $\left(\mathrm{R}^{2}, \mathrm{Q}^{2}\right.$, RMSEC and RMSEP) are assessed. The raw data results are indicated in Table $3 \mathrm{~b}$, models with $4 \mathrm{LVs}$ for Tiz and with 5 LVs for A, E, A-B and T classes were developed. The models for the reduced data were developed with $4 \mathrm{LVs}$ for A, E,Tiz and with $5 \mathrm{LVs}$ for A-B and T classes (Table $3 c$ ). As presented in Tables $4 \mathrm{~b}$ and $4 \mathrm{c}$, the 30 test set samples are clearly assigned to the proper classes with predicted values $0.700-1.080$ and $0.938-1.060$ for the raw and the reduced data sets, respectively. The PLS-DA models from both data sets showed excellent predictive abilities in classifying the samples from the five regions. The PLS-DA models gave a good prediction and an accurate discrimination with $100 \%$ correct classification rate of the external validation set samples. The results from both the raw and the reduced data sets are better than those from the models build from the chemical composition.

It can be concluded that the combination of FTIR spectra and chemometric tools, such as PCA and PLS-DA, allowed the fast discrimination and classification of the different PGI Argan oils samples according to their geographical origin.

\section{Conclusions}

The present work is the first comprehensive study to classify PGI Argan oil samples from five different regions of Morocco. One hundred twenty samples harvested between 2011 and 2014 were, on the one hand, chemically characterized, through the determination of free acidity, peroxide content, spectrophotometric parameters, tocopherols, fatty acids, sterols and through FTIR fingerprinting, on the other. The chemical composition data and the FTIR spectra, combined with chemometric tools allow relating the PGI Argan oils to their geographical origin. PCA on the chemical composition was able to discriminate the five regions, while PCA on the FTIR spectra gave an even better discrimination. PLS-DA models were capable of classifying correctly the PGI Argan oil samples according to their geographical origin. However, the measurement of the FTIR spectra is much faster and easier than the chemical composition determination of the samples. The FTIR spectra approach thus may be highly recommended as a fast alternative to the chemical profiling for the geographical classification of the oils.

Finally it should be noted that the results are of great interest, to assure the traceability of Moroccan Argan oil and to contribute to the 


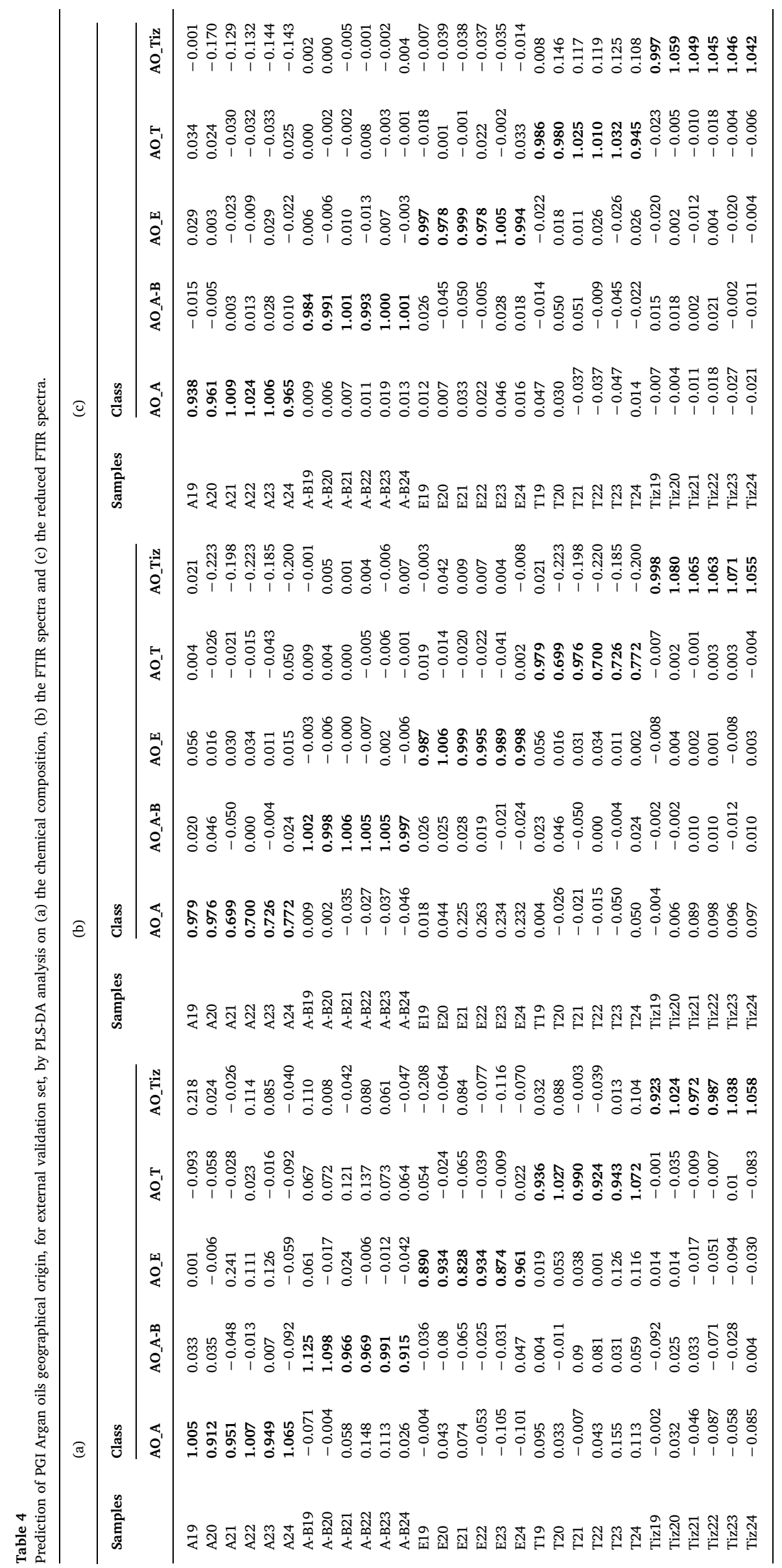



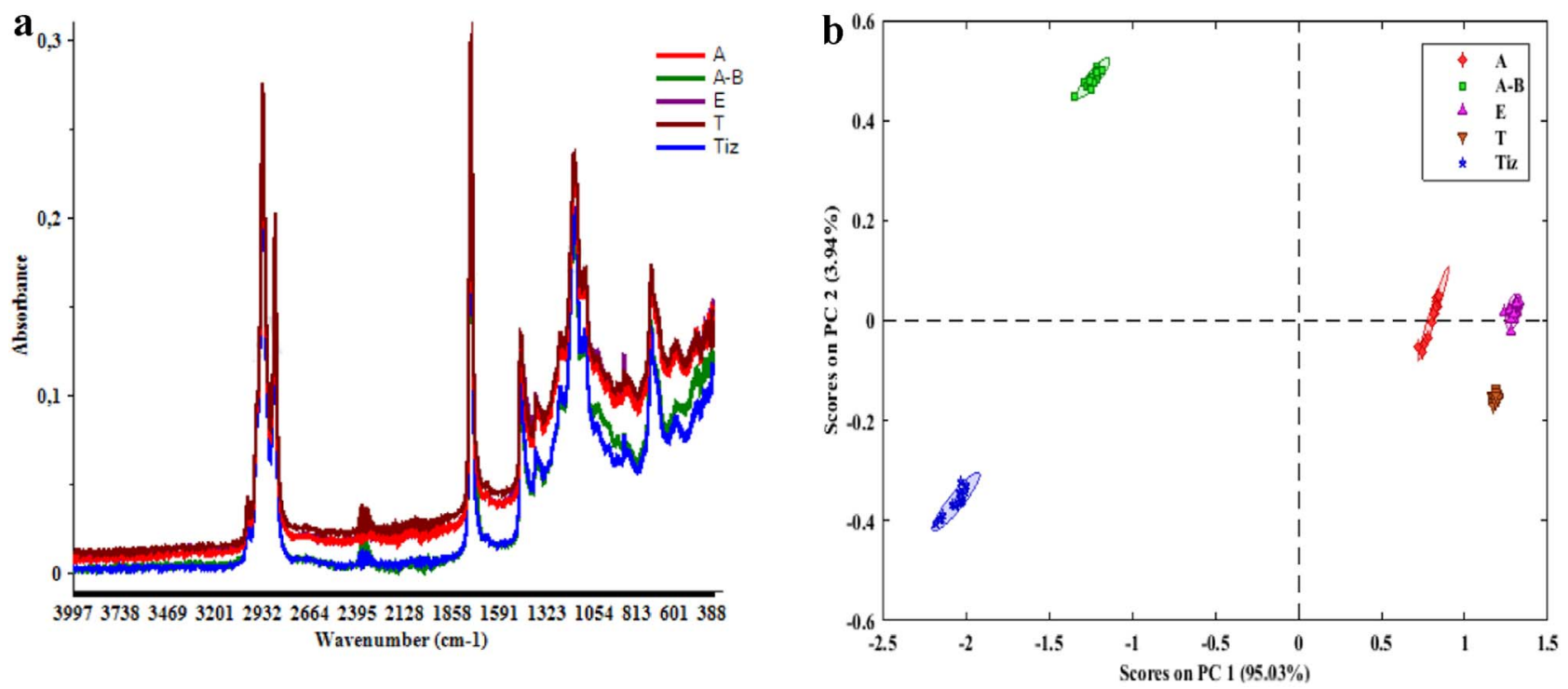

Fig. 3. (a) FTIR spectra for the PGI Argan oil samples. (b). Scores plot, PC1vs PC2, on the reduced FTIR spectra.

quality value of the Protected Geographical Indication label of these samples.

\section{Acknowledgements}

The authors are grateful to the Women Cooperatives Markets from Ait-Baha, Agadir, Essaouira, Tiznit and Taroudant for providing the Argan oil samples. They appreciate the Mohammed VI Foundation for Research and Protection of the Argan Tree for supporting this project. The Fonds Wetenschappelijk Onderzoek - Vlaanderen (FWOValaanderen) (G038816N) and the Vrije Universiteit Brussel (VUB) are thanked for financial support.

\section{References}

[1] Z. Charrouf, D. Guillaume, Argan oil: occurrence, composition and impact on human health, Eur. J. Lipid Sci. Technol. 110 (2008) 632-636.

[2] Z. Charrouf, D. Guillaume, Argan oil, the 35yearsofresearch product, Eur. J. Lipid Sci. Technol. 116 (2014) 1316-1321.

[3] A. Rueda, I. Seiquer, M. Olalla, R. Giménez, L. Lara, C. Cabrera-Vique, Characterization of fatty acid profile of argan oil and other edible vegetable oils by gas chromatography and discriminant analysis, J. Chem. 2014 (2014) 1-8.

[4] F. Khallouki, C. Younos, R. Soulimani, T. Oster, Z. Charrouf, B. Spiegelhalder, H. Bartsch, R. Owen, Consumption of argan oil (Morocco) with its unique profile of fatty acids, tocopherols, squalene, sterols and phenolic compounds should confer valuable cancer chemopreventive effects, Eur. J. Cancer Prev. 12 (2003) 67-75.

[5] R. Maurin, K. Fellat-Zarrouk, M. Kirs, Huile d'argan, Argania spinosa du Maroc, Triglycérides, Actes du congres, Euro-lipid, Angers, 1989, pp. 151-158.

[6] Z. Charrouf, D. Guillaume, Ethnoeconomical, ethnomedical, and phytochemical study of Argania spinosa (L.) Skeels, J. Ethnopharmacol. 67 (1999) 7-14.

[7] Z. Charrouf, M. Hilali, O. Jauregui, M. Soufiaoui, D. Guillaume, Separation and characterization of phenolic compounds in argan fruit pulp using liquid chromatography-negative electrospray ionization tandem mass spectroscopy, Food Chem. 100 (2007) 1398-1401.

[8] H.E. Monfalouti, D. Guillaume, C. Denhez, Z. Charrouf, Therapeutic potential of argan oil: a review, J. Pharm. Pharmacol. 62 (2010) 1669-1675.

[9] M. Hilali, Z. Charrouf, A.E. Aziz Soulhi, L. Hachimi, D. Guillaume, Influence of origin and extraction method on argan oil physico-chemical characteristics and composition, J. Agric. Food Chem. 53 (2005) 2081-2087.

[10] R. Consonni, L. Cagliani, Nuclear magnetic resonance and chemometrics to assess geographical origin and quality of traditional food products, Adv. Food Nutr. Res. 59 (2010) 87-165.

[11] A. Gonzalvez, S. Armenta, M. De La Guardia, Trace-element composition and stableisotope ratio for discrimination of foods with Protected Designation of Origin, TrAC Trends Anal. Chem. 28 (2009) 1295-1311.

[12] M. Hilali, Z. Charrouf, A.E.A. Soulhi, L. Hachimi, D. Guillaume, Detection of argan oil adulteration using quantitative campesterol GC-analysis, J. Am. Oil Chem. Soc. 84 (2007) 761-764.

[13] F.A. Mohammed, R. Bchitou, A. Bouhaouss, S. Gharby, H. Harhar, D. Guillaume, Z. Charrouf, Can the dietary element content of virgin argan oils really be used for adulteration detection? Food Chem. 136 (2013) 105-108.

[14] R. Salghi, W. Armbruster, W. Schwack, Detection of argan oil adulteration with vegetable oils by high-performance liquid chromatography-evaporative light scattering detection, Food Chem. 153 (2014) 387-392.

[15] D.M. Luykx, S.M. Van Ruth, An overview of analytical methods for determining the geographical origin of food products, Food Chem. 107 (2008) 897-911.

[16] A. Bendini, L. Cerretani, F. Di Virgilio, P. Belloni, M. BonoliCarbognin, G. Lercker, Preliminary evaluation of the application of the FTIR spectroscopy to control the geographic origin and quality of virgin olive oils, J. Food Qual. 30 (2007) 424-437.

[17] H.S. Tapp, M. Defernez, E.K. Kemsley, FTIR spectroscopy and multivariate analysis can distinguish the geographic origin of extra virgin olive oils, J. Agric. Food Chem. 51 (2003) 6110-6115.

[18] M. Palma, C. Barroso, Application of FT-IR spectroscopy to the characterisation and classification of wines, brandies and other distilled drinks, Talanta 58 (2002) 265-271.

[19] M. Bassbasi, M. De Luca, G. Ioele, A. Oussama, G. Ragno, Prediction of the geographical origin of butters by partial least square discriminant analysis (PLS-DA) applied to infrared spectroscopy (FTIR) data, J. Food Compos. Anal. 33 (2014) 210-215.

[20] A. Rohman, Y.C. Man, Fourier transform infrared (FTIR) spectroscopy for analysis of extra virgin olive oil adulterated with palm oil, Food Res. Int. 43 (2010) $886-892$.

[21] M. Lerma-García, G. Ramis-Ramos, J. Herrero-Martínez, E. Simó-Alfonso, Authentication of extra virgin olive oils by Fourier-transform infrared spectroscopy, Food Chem. 118 (2010) 78-83.

[22] A. Oussama, F. Elabadi, O. Devos, Analysis of argan oil adulteration using infrared spectroscopy, Spectrosc. Lett. 45 (2012) 458-463.

[23] S. Jawaid, F.N. Talpur, S. Sherazi, S.M. Nizamani, A.A. Khaskheli, Rapid detection of melamine adulteration in dairy milk by SB-ATR-Fourier transform infrared spectroscopy, Food Chem. 141 (2013) 3066-3071.

[24] M.P. Aguilera, G. Beltrán, D. Ortega, A. Fernández, A. Jiménez, M. Uceda, Characterisation of virgin olive oil of Italian olive cultivars: 'frantoio'and 'Leccino', grown in Andalusia, Food Chem. 89 (2005) 387-391.

[25] F. Longobardi, A. Ventrella, G. Casiello, D. Sacco, M. Tasioula-Margari, A. Kiritsakis, M. Kontominas, Characterisation of the geographical origin of Western Greek virgin olive oils based on instrumental and multivariate statistical analysis, Food Chem. 133 (2012) 169-175.

[26] N. Tzouros, I. Arvanitoyannis, Agricultural produces: synopsis of employed quality control methods for the authentication of foods and application of chemometrics for the classification of foods according to their variety or geographical origin, Crit. Rev. Food Sci. Nutr. 41 (2001) 287-319.

[27] K. Schlesier, C. Fauhl-Hassek, M. Forina, V. Cotea, E. Kocsi, R. Schoula, F. van Jaarsveld, R. Wittkowski, Characterisation and determination of the geographical origin of wines, Part I: Overv., Eur. Food Res. Technol. 230 (2009) 1-13.

[28] H.A.T. Regulation, Commission regulation (EEC) No. 2568/91 of 11 July 1991 on the characteristics of olive oil and olive-residue oil and on the relevant methods of analysis, Off. J. Eur. Communities 248 (1991) 1-83.

[29] AOCS, Official methods and recommended practises of the American Oil ChemistSociety, 5th Champaign, Illinois, 〈https://aocs.personifycloud.com/ PersonifyEBusiness/Default.aspx?TableID $=251 \&$ productId $=114014>$ (accessed 11.01.17), 1998

[30] International Standard Iso 12228, Animal and vegetable fats and oils determination of individual and total sterols contents-gas chromatographic method, 〈http:// www.iso.org/iso/home/store/catalogue_tc/catalogue_detail.htm? Csnumber $=60249>$ (accessed 11.01.17), 2014.

[31] P. Geladi, Chemometrics in spectroscopy. Part 1. Classical chemometrics, Spectrochim. Acta Part B: At. Spectrosc. 58 (2003) 767-782.

[32] D. Ballabio, V. Consonni, Classification tools in chemistry. Part 1: linear models. PLS-DA, Anal. Methods 5 (2013) 3790-3798. 
[33] L.A. Berrueta, R.M. Alonso-Salces, K. Héberger, Supervised pattern recognition in food analysis, J. Chromatogr. A 1158 (2007) 196-214.

[34] N. Marocaine, Service de normalisation industrielle marocaine, Huile d 'argane. Spécifications. NM, 8090, 〈http://www.imanor.ma/index.php/Information/ Catalogue-des-normes-marocaines $\rangle$ (accessed 11.0.2017), 2003.

[35] B. Matthäus, D. Guillaume, S. Gharby, A. Haddad, H. Harhar, Z. Charrouf, Effect of processing on the quality of edible argan oil, Food Chem. 120 (2010) 426-432.

[36] M. Rahmani, Composition chimique de l'huile d'argane «vierge», Cah. Agric. 14 (2005) 461-465.

[37] R. Belcadi-Haloui, A. Zekhnini, A. Hatimi, Comparative Study on Output and Chemical Composition of Argan Oils Extracted from Fruits of Different Regions in the Southwest of Morocco, Food Sci. Qual. Manag. 30 (2014) 1-6.

[38] N.A. Aabd, A. El Asbahani, Y. El Alem, A. El Finti, F. Msanda, A. El Mousadik, Variation in oil content and fatty acid composition in preselected argan trees with morphological characters and geographical localization, Mediterr. J. Nutr. Metab. 6 (2013) 217-225.
[39] A. Kamal-Eldin, L.-Å. Appelqvist, The chemistry and antioxidant properties of tocopherols and tocotrienols, Lipids 31 (1996) 671-701.

[40] W.L. Stone, A. Papas, F. Gunstone, Tocopherols, tocotrienols and vitamin E, Lipids Funct. Foods Nutraceuticals (2003) 53-72.

[41] S. Gharby, H. Harhar, D. Guillaume, A. Haddad, B. Matthäus, Z. Charrouf, Oxidative stability of edible argan oil: a two-year study, LWT-Food Sci. Technol. 44 (2011) 1-8.

[42] H. Harhar, S. Gharby, B. Kartah, H. El Monfalouti, D. Guillaume, Z. Charrouf, Influence of argan kernel roasting-time on virgin argan oil composition and oxidative stability, Plant Foods Human. Nutr. 66 (2011) 163-168.

[43] H. Yang, J. Irudayaraj, M.M. Paradkar, Discriminant analysis of edible oils and fats by FTIR, FT-NIR and FT-Raman spectroscopy, Food Chem. 93 (2005) 25-32.

[44] N. Sinelli, L. Cerretani, V. Di Egidio, A. Bendini, E. Casiraghi, Application of near (NIR) infrared and mid (MIR) infrared spectroscopy as a rapid tool to classify extra virgin olive oil on the basis of fruity attribute intensity, Food Res. Int. 43 (2010) 369-375. 